height is 6 inches for the curve $A$, and $I$ foot for the curve $B$. It is obvious that, in judging of the safety of small metacentric height for such a vessel, the range of stability is an important factor to be considered. The range necessary for seaworthiness largely determines and often fixes the limit below which the metacentric height should not be reduced in such a type of ressel and in many others.

But there are very large numbers of steamers, such as passenger liners and cargo steamers, of the spar and awning-deck classes, which generally have very large ranges of stability, and large righting moments at great angles of inclination, whatever the metacentric height may be ; and in many cases, even with no metacentric height at all. In such cases the minimum metacentric height which is essential to safety and efficiency has to be determined by entirely different considerations from those which apply to war ships, and those classes of mercantile steamers whose stability is of the character shown by the curves in Fig. 2. When we have to deal with vessels which even with no metacentric height will return to the upright, provided water does not get into the ship, and no large weights shift, whatever angle of inclination may be reached, the conditions of the problem are entirely changed. The principal object which then has to be
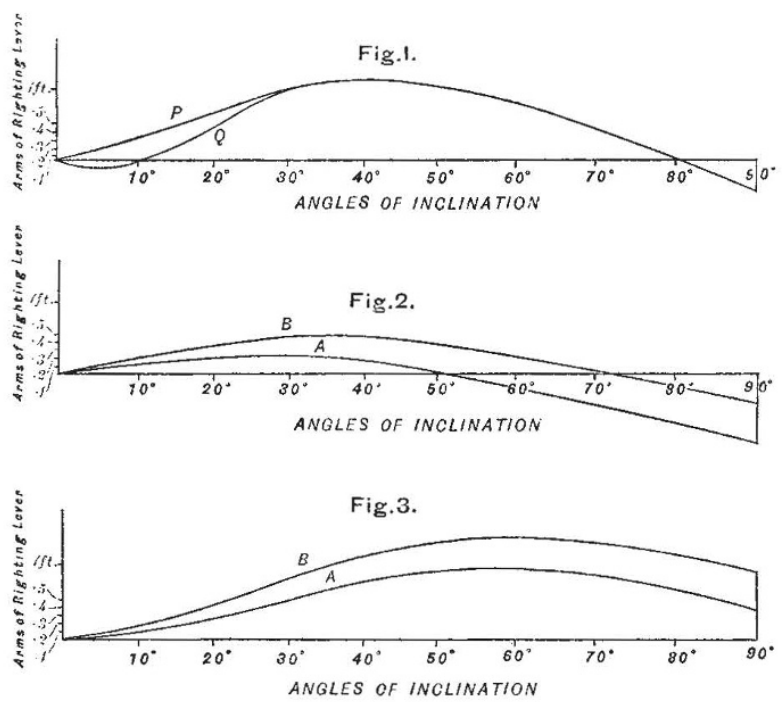

Fig.4.

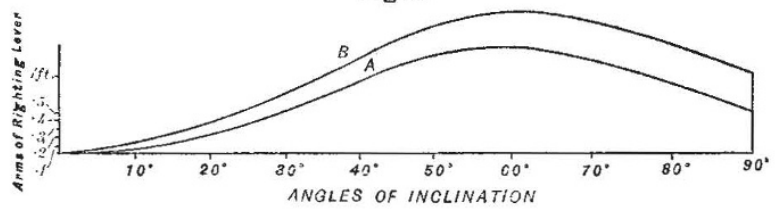

considered is to prevent too easy an inclination from the upright by the action of the wind and other forces which may operate upon her; and the question mainly turns upon what may fairly be considered sufficient for this purpose.

Many persons have been surprised on first learning how little metacentric height many high-sided mercantile steamers are in the habit of working with in safety. There are many steamers of the spar and awning-deck classes employed in carrying homogeneous cargoes, which have been performing their work for years, not only with perfect safety but without showing any signs of what nautical men call tenderness, the metacentric heights of which, during certain periods of their voyages, are frequently not more than 8 inches or even 6 inches. The latter figure may probably be regarded as about the minimum which such vessels approach without indicating to those on board that they are becoming unduly tender : but it is quite certain that many never show any such signs, and appear to be perfectly safe with 8 inches of metacentric height.

Vessels of this class have curves of stability of which those shown in Figs. 3 and 4 are types. The curves in Fig. 3 are for a spar-decked steamer 318 feet by 40 feet by 22 feet. The load draught is 23 feet 6 inches, and displacement 5760 tons; the freeboard being 8 feet 6 inclies. Those in Fig. 4 are also for a spar-decked steamer 220 feet by 30 feet by 23 feet. The load draught is $\mathbf{I} 6$ feet, and displacement 2000 tons; the freeboard being 8 feet 6 inches. The curves marked $A$ in each of these figures are constructed for 6 inches of metacentric height, and those marked $B$ for $\mathbf{I}$ foot, in order that they may be compared with the corresponding curves in Fig. 2. The metacentric height of 6 inches is about what cach of these vessels would have if laden to the draughts named with homogeneous cargoes, such as they frequently carry ; and the metacentric heights of I foot are obtained by leaving a portion of such cargo out of the 'tween decks, and replacing it by an equal weight of ballast in the bottom.

It will be seen that the increase of righting moment in Figs. 3 and 4 continues up to a very large angle of inclination. This increase of righting moment tends to prevent dangerous inclinations being reached, while the smallness of the metacentric height causes such vessels to be very easy and comfortable in a seaway. Some steamers whose stability is of this character are vessels which carry cargoes liable to shift, such as grain or coals, and it may be thought that with cargoes of this class a small metacentric height is particularly unsafe, and that considerable initial stiffness is necessary to prevent any danger arising through shifting of cargo. Any opinions that may be formed upon this point are necessarily more or less speculative, as we have but little exact information to go by ; but it should be borne in mind, in considering the question of initial stiffness in connection with shifting cargoes, that, although such stiffness increases the resistance to inclination, it increases at the same time the tendency to roll, and to displace or shift the cargo.

The question of the minimum metacentric height which may be regarded as consistent with safety in those types of ships where it is not governed in any degree by the necessity of providing range of stability, as shown by Figs. 3 and 4 , is a subject which has never been much discussed, and which, on account of its important and immediate bearing upon the safety of many vessels at sea, is, in my opinion, deserving of the consideration of this Institution. If any of the remarks contained in this paper should serve to elicit opinions, information, or facts bearing upon the subject, my purpose in making them will be answered.

I may add, in conclusion, that the following are the main points which I have desired to lay before the Institution in this paper :-(I) The form in which the results of stability calculations can be put before owners and masters of mercantile steamers, so as to be of the greatest practical use in loading such steamers, and regulating their stability in accordance with the requirements that may arise; (2) the fundamental difference which exists between the relation of righting moments at large angles of inclination and range of stability to metacentric height in the various types of steamers, as shown by Figs. 2, 3, and 4 , such relation making it necessary to fix the minimum metacentric height that should be allowed with due regard to the righting moments at large angles of inclination in some cases and unnecessary to do so in others; and (3) the minimum metacentric height that may be regarded as consistent with safety in cases where range of stability and the righting moments at large angles of inclination are so ample as not to call for consideration. The two latter points are so intimately connected with the first that they naturally require to be considered along with it.

\section{THE INSTITUTION OF NAVAL ARCHITECTS}

THE Institution of Naval Architects held its twenty-fifth Session at the Rooms of the Society of Arts on A pril 2, 3, and 4, Iord Ravensworth in the chair. Whilst the papers read were of course mainly on technical questions of naval construction, equipment, \&c., some of them possessed points of general scientific interest, of which a brief account may be given. The President's addiress dealt mainly with what may be called the economic side of the shipping industry, dwelling on such points as the Merchant Shipping Bill, the length of time occupied in building ships of war, the depression of the carrying trade, \&c. Passing on to the papers contributed, the first read was by Mr. J. D. Samuda on the Riachuelo, a steel armour-clad twin screw turret-ship of 6000 tons displacement, and 6000 horse-power, lately built by his firm for the Brazilian Government.

The second paper, by Mr. A. F. Yarrow, was on an Electrical Launch tried last year both on the Thames and on the Danube, 
and aiready mentioned in these columns. It dealt with the question from a practical and not an electrical point of view, and is so far valuable as presenting a fresh aspect of the question. On the whole the author's conclusions are satisfactory. He considers that there is even now a field for electrical launches in cases where the conditions are favourable, such as having a supply of cheap motive power for recharging the batteries; and that they are pre-eminently adapted for torpedo boats, owing to their being always ready for action, and their complete noiselessness when in motion. On the whole the advantages and disadvantages as compared with the steam-launch are summed up by Mr. Yarrow as follows, beginning with the former :-

I. Entire absence of noise.

2. Great cleanliness.

3. The whole of the boat is available for passenger accommodation, the midship or best part of it not being occupied by machinery.

4. When once charged it is ready for use at a moment's notice.

The points against it are :-

r. Difficulty and delay from frequent charging.

2. Greater first cost.

3. Greater cost of working in those cases where an engine has specially to be laid down for the purpose of charging.

The third paper read was on the Vibration of Steam-vessels, by Mr. Otto Schlick, which dealt with the shaking so well known to passengers on screw steamers from the practical and theoretical point of view. It is shown clearly that the phenomenon is merely due to the fact that the ship, considered as an iron girder, has one or more fixed periods of vibration depending on her length, her width, and other dimensions. With regard to the practical means of overcoming such vibrations, it is pointed out that anything which causes the engine to run at a different speed, for instance, the putting in of a new propeller, will probably have a favourable effect. The shifting of the screw to a different angle with regard to the cranks is recommended as often giving a good result, inasmuch as two of the forces causing the vibration may be balanced one against the other. An ingenious apparatus for measuring such vibrations is described by the author.

The morning of April 3 was occupied during the whole period of five hours by the reading and discussion of three papers on the burning question of Stability. One of these, on the Use of Stability Calculations in Regulating the Loading of Steamers, by Prof. Elgar, we print at length. Another, on Cross Curves of Stability, was read by Mr. W. Denny, the well-known shipbuilder of Dumbarton. He observes that stability curves are required for at least four draughts of any steamer, viz. the launching condition, the condition completely finished, but without any cargo, coals, \&c., on board, the fully loaded condition, and the condition with the coals consumed. If the stability curve be also calculated for an intermediate draught between the second and third of these, five points will be obtained at each angle, by means of which a cross curve of stability can be produced. It is therefore of great importance to work out such cross curves and to find a method by which they can be readily constructed from the ordinary curves of stability. A method for doing this with the assistance of Amsler's Integrator has been devised, and when drawn the curves are also represented by means of a solid model. These cross curves are each for a given angle, and have the length of the righting arm varying with the draught or displacement. With such cross curves in number sufficient to cover angles at intervals of $10^{\circ}, 15^{\circ}$, and $20^{\circ}$, and each ranging through all the draughts from the launched to the loaded condition, ordinary curves at any draught and with any height of centre of gravity can be easily obtained, and with great rapidity. The method employed is fully described, as is also another method due to $\mathrm{Mr}$. Couwenberg. Tables are also given showing the results obtained for the same steamer by the two methods, which, though worked out separately, were found to agree very closely.

The third paper was on a New Method for Calculating the Stability of Ships, by M. Daymond. This is an elaborate paper of a theoretical character, illustrated with numerous diagrams. It gives the history of the means adopted for calculating stability, especially the method invented by M. Ferranti. The author's own method is an improvement on this. Having made for various ships numerous drawings which showed on the vertical section of the ship, in length and in direction, the arms of the righting levers, for various draughts and inclinations, he conceived the idea of joining by continuous lines the extremities of these arms corresponding to the same angle of inclination.
Taking such angles at intervals of $10^{\circ}$, he thus obtains a curve which he calls the "pantocarcine isocline," and from these curves he obtains at once with complete accuracy and for all possible cases the usual curves of statical stability. The paper gives the principal properties of these curves, together with the mode of their calculation and various examples of working. 'The paper had been translated by Sir E. J. Reed, who may therefore be considered to have lent his authority to the value of the method proposed. 'The discussion on these papers turned mainly on unimportant and to some extent personal questions, and, though animated, does not need production here.

On Thursday evening, April 3, the most important paper was one by Mr. James Howden on Combustion of Fuel in Furnaces and Steam Boilers by Natural Draught and by Supply of Air under Pressure. The object of it was to describe a new boiler on which the author was experimenting, and which, if his account be correct, is likely to realise very important advantages in the way of economy of fuel. The experiments are not concluded, but the author considers them to justify him in claiming a most extraordinary economy as compared with ordinary marine boilers. Taking the instance of the Oregon, the latest-built of the swift Atlantic liners, he professes that the coal consumption might be reduced from $3 \mathbf{I}, 000$ to 19,000 lbs, per hour, with an equal supply of steam and with a diminution in the fire-grate surface from I 512 to only 64I square feet. In the discussion which ensued very grave doubts were expressed as to the reality of such a saving, and it would probably have been more wise if the author had completed his experiments before claiming so very large a step in advance.

The next paper, by Mr. A. B. Broun, on the Application of Hydraulic Machinery to the Loading, Sc., of Steamships, gave an interesting account of a complete hydraulic system applied to all the work required in an ordinary vessel, but did not raise any theoretical questions. A paper was then read by Mr. J. Ji. Hall, on Cast Steel as a Material for Crank Shafts. The author, who belongs to the well known firm of Messrs. Jessop of Sheffield, advocated the making of these important parts of a ship by the ordinary method of casting steel, without any subsequent hammering or working. His view is that such hammering can never reach the centre of a large mass of steel, such as an ingot; and that even if it did it would not completely weld up and remove the cavities which are not infrequently foundi in that region. In fact his view was that forging actually did harm by consolidating the outer layers and preventing them from contracting subsequently, as the hotter interior shrank in its cooling. By using ordinary methods of casting, and taking care to have a sufficient head or column of metal standing up above the casting itself, ho considered that all fear of cavities within the latter was removed. Any unsoundness would be found only within the column, which would of course be cut off when the casting was cool.

The remaining papers, read on Friday, will not require any extended notice. That of Mr. P. Jenkins, on the Construction of Metacentric Diagrams, was a theoretical paper, dealing with the problem of stability, and chiefly devoted to establishin the following theorem:-- "For any position of the centre of gravity the initial righting moment is either a maximum or a minimum when the water plane is so placed that the centre of curvature of the curve of flotation is at the same height in the vessel as the centre of gravity." Another contribution to the same problem, that of stability, was read by Mr. S. Benjamin, and described a model or apparatus enabling a shipowner to determine the position of the centre of gravity of his vessel for any loading before she is loaded, and also the alteration of its position due to any subsequent change in the loading. Yet another paper, by Dr. A. Amsler, described the application of the integrating apparatus which bears that name to such calculations as those of the curves already mentioned in Mr. Denny's paper. Mr. J. E. Spence described a form of diagram exhibiting in a simple shape all the data depending on the form of a ship which are required for determining her stability, and also a simple and direct method of graphic calculation for attaining these data. Mr. Thomas I'hiliips read a paper on the comparative safety of the particular class of vessels known as "well-decked" steamers. These were formerly treated with some suspicion by underwriters, but great improvements have lately been made, some of which were described in the paper, and with these the vessel appears to be even safer than what are called "flush" ships. Lastly, Mr. A. Taylor described a special instrument invented by him, and called a.Stability Indicator, for determining the initial stability and stowage of ships at any displacement. 
Mr. H. H. West read a paper on the Riveting of Iron Ships, giving tables for calculating the plate and rivet area for doubleriveting, treble-riveting, and quadruple-riveting. He referred to the researches of Sir Edward Reed, the Institution of Mechanical Engineers, and others, but did not mention the modification of treble-riveting proposed some years ago, and lately carried into effect by a firm in Holland. On this system, in the middle row of the three rows of rivets, the rivets are spaced only half the distance apart of the two outer rows, the result being to increase very largely the proportion of strength. Capt. Heathorn described an arrangement called by him a Water-brake, for stopping the way of a ship in cases of collision or otherwise ; and finally, Mr. J. E. I iardet described an apparatus for indicating the position of a ship's helm.

On the whole the Institution is to be congratulated on the interest and importance of the papers provided for it, and still more on the vigour and ability with which they were discussed by the very eminent engineers and shipbuilders who thronged the rooms of the Society of Arts for the purpose.

\section{SCIENTIFIC SERIALS}

Bulletin de l'Académie $R$. de Belgique, January 5.-On the existence of a fourth species ( $B$. borealis) of the genus Balænoptera in the North Atlantic and Arctic Oceans, by M. Guldberg. - On the action of chlorine on combinations of sulphur, and on organic oxysulphurets, third communication, by M. W. Spring.--Researches on spermatogenesis in the Selacians (Scyllium catulus, Sc. canicula, Raja clavata), the salamander and mammals, by Prof. A. Swaen.-Essays on the political history of the last three centuries, by M. Van Praet.-Biographical notice of the painter Michael Van Cocxyen of Mechlin, by M. Castan.

Atti della $R$. Accademia dei Lincei, January 20.-Letter from King Humbert announcing an additional annual grant of $400 l$. for the promotion of biological studies, to be distributed in prizes in any way the Academy may think fit.-Some philological remarks on the 104th Psalm, by Guidi Ignazio.--Notice of an unpublished work of Prince Federico Cesi, entitled "De Laserpiteo et Laserpitii pluvia," in the library of the Botanic Institute at Padua, by Prof. A. Favaro. - Note on the antiquities discovered at Ventimiglia, Montefiascone, Naples, Pompeii, and other parts of Italy during the month of December I883, by S. Fiorelli.

February 3 and 4 - -Notice of some unpublished writings of Galileo Galilei in the National Library of Florence, by Prof. Favaro,- - Report on Prof. Bellonci's work "On the Segmentation of the Egg of the Axolotl," by S. Trinchese.-Report on Dr. G. Frattini's work "On Some Propositions in the Theory of Substitutions," by S. Battaglini.-Report on Dr. L. Macchiati's work on the chemical nature of chlorophyll, by S. Cannizzaro. - Observations of the solar spots and facula made at the Observatory of the Collegio Romano during the year 1883 , by Pietro Tacchini. - On the temperature corresponding to the (ilacial period, third note, by Pietro Blaserna.-On the extraordinary crepuscular phenomena observed during the last few months, by Lorenzo Respighi.-Contributions to the study of the carbopyrolic acid $\alpha$, by G. L. Ciamician and Paolo Silber.Remarks on the Veronese Chelonian (Protosphargis veronensis) discovered in $\mathbf{1} 852$ in the Upper Chalk near St. Anna di Alfaedo in Valpolicella, by Giovanni Capellini.-Geological observations on the islands of the Tuscan Archipelago, by B. Lotti.-Reports on the competition for the Royal Prizes for Physics, History, and Geography for the year 1882, by Signor Cantoni and Villari.-Reports on the Ministerial prizes for the Philosophical, Social, and Natural Sciences for the year I883, by Signors Bonatelli and Trinchese.

February 17.-Obituary notices of the late Pietro Canal and Edoardo Laboulaye, Members of the Academy, by the President. -On the practice of burying human bones stripped of the flesh in Neolithic times, by Luigi Pigorini. - Note on the antiquities discovered at Felonica, Este, Imola, and in other parts of Italy during the month of January I884. - Remarks on some codices in the Angelica Library connected with patristic theology, by Enrico Narducci. - Note on the parabolic orbit of the comet $(e)$ discovered by Hartwig at Strasburg on August 24, I879, by E. Millosevich.-On a remarkable disposition of the isogonic lines of terrestrial magnetism observed in the eastern districts of the Valley of the Po (two illustrations), by Ciro Chistoni.
Rivista Scientifico-Industriale, February 15 and 29.-Description of a new apparatus for the measurement of electro-motor forces (four illustrations), by E. Reynier.-Mathematical demonstration and value of the angle of least deviation described by a ray of light in its passage through a prism (one illustration), by Giuseppe Vanni. - Practical determination of the metallic resistance and chemical reaction of an electrolytic circuit, by Eugenio Marchese. - On the causes of the remarkable after-glows witnessed in Italy and elsewhere in I883-84, by Prof. Carlo Marangoni. The author compares these phenomena with others of an analogous character observed in various parts of Europe in the year 1869. On several grounds he infers that the pink and red glows could not have been produced by moisture disseminated in the atmosphere in the solid, liquid, or gaseous state. He concludes that they are due to the presence of dust or minute particles of sand, which absorb the coloured rays in the central region of the solar spectrum while transmitting the extreme colours-that is, red and violet. The paper, which is to be continued, offers no suggestion as to the possible origin of the particles of dust to which the phenomena are attributed.--Note on the extinct and living mollusks of the Gardone district, by Prof. Strobel.-On the fossil insects of the Carboniferous schists of Commentry, by S. Brongniart. - Note on the limits of diatomaceous vegetation in marine basins, by Count A. F. Castracane.

Rendiconti del Reale Istituto Lombardo, February 21.-Biographical notice of Carlo Tenca and his times, by Prof. Giovanni Cantoni.--Some reflections on the results of the recent examinations in the Italian language and literature in the higher schools of the Peninsula, by Prof. C. Baravalle. - Fresh researches on the oxidation of sulphur, with some remarks on the oxidising power of the so-called atomic oxygen and of ozone, by Prof. E. Pollacci.... On some cases of subcutaneous nervous affections caused by the presence of Oscyuris, Tænia, Solium, and other parasites, by Prof. A. Scarenzio.--On the relations between the malady known as "bronze skin," and the changes in the suprarenal blood capsules, by Prof. G. Sangalli.-Meteorological observations made in the Brera Observatory, Milan, during the month of February 1884

\section{SOCIETIES AND ACADEMIES LONDON}

Royal Society, March 27.-- "On the Electro-chemical Equivalent of Silver, and on the Absolute Electromotive Force of Clark Cells." By Lord Rayleigh, D.C.L., F.R.S.

The investigations upon this subject which have been carried on by Mrs. Sidgwick and myself during the last year and a half, though not yet quite finished, are so far advanced that no doubt remains as to the general character of the results; and as these results have application in the daily work of practical electricians, it is thought desirable to communicate them without further delay.

The currents are measured by balancing the attraction and repulsion of coaxal coils against known u eights, as described before the British Association in 1882, a method which has fully answered the favourable expectations then expressed. To what was said on that occasion it will be sufficient for the present to add that the readings are taken by reversal of the current in the fixed coils, and the difference of weights thus found (abcut grm.) represents the double force of attraction free from irrors depending upon the connections of the suspended coil, ar d other sources of disturbance.

The difficulties which have been experienced, and wrich have been the cause of so much delay, have related entirely to th: behaviour of the silver voltameters, of which never less than two, ard sometimes as many as five, have been included in the circuit of the measured current. In order to render the deposit more compact, and thus to diminish the danger of loss in the subsequent manipulations, acetate of silver was added in the earlier experiments to the standard solution of nitrate. Experience, however, has shown that the principal risk is not in the loss of metal, but in the obstinate retention of salt within the fine pores of the deposit, leading to an over-estimate of the amount. When the texture is very compact, this danger in. creases, and deposits from a solution containing acetate are often decidedly too heavy, even after the most careful and protracted washings. On heating to low redness a portion, at any rate, of the retained salt is decomposed NOg is driven off, and a loss of 